\title{
Starting to Unpick the Unique Air-Fuel Mixing Dynamics in the Recuperated Split Cycle Engine
}

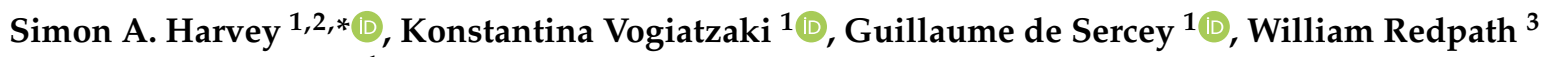 \\ and Robert E. Morgan ${ }^{1}$ \\ 1 Advanced Engineering Centre, University of Brighton Cockroft Building, Lewes Road, Brighton, \\ East Sussex BN2 4GJ, UK; k.vogiatzaki@brighton.ac.uk (K.V.); G.DeSercey@brighton.ac.uk (G.d.S.); \\ r.morgan2@brighton.ac.uk (R.E.M.) \\ 2 Ricardo Innovations, Shoreham Technical Centre, Shoreham-by-Sea, West Sussex BN43 5FG, UK \\ 3 Advanced Manufacturing Research Centre, University of Sheffield, Sheffield S60 5TZ, UK; \\ w.redpath@sheffield.ac.uk \\ * Correspondence: s.harvey2@brighton.ac.uk
}

Citation: Harvey, S.A.; Vogiatzaki, K.; de Sercey, G.; Redpath, W.; Morgan, R.E. Starting to Unpick the Unique Air-Fuel Mixing Dynamics in the Recuperated Split Cycle Engine. Energies 2021, 14, 2148. https:// doi.org/10.3390/en14082148

Academic Editor: Michele Battistoni

Received: 22 February 2021

Accepted: 31 March 2021

Published: 12 April 2021

Publisher's Note: MDPI stays neutral with regard to jurisdictional claims in published maps and institutional affiliations.

Copyright: (C) 2021 by the authors Licensee MDPI, Basel, Switzerland. This article is an open access article distributed under the terms and conditions of the Creative Commons Attribution (CC BY) license (https:// creativecommons.org/licenses/by/ $4.0 /)$.

\begin{abstract}
In this work air fuel mixing and combustion dynamics in the recuperated split cycle engine (RSCE) are investigated through new theoretical analysis and complementary optical experiments of the flow field. First, a brief introduction to the basic working principles of the RSCE cycle will be presented, followed by recent test bed results relevant to pressure traces and soot emissions. These results prompted fundamental questioning of the air-fuel mixing and combustion dynamics taking place. Hypotheses of the mixing process are then presented, with differences to that of a conventional Diesel engine highlighted. Moreover, the links of the reduced emissions, air transfer processes and enhanced atomisation are explored. Initial experimental results and Schlieren images of the air flow through the poppet valves in a flow rig are reported. The Schlieren images display shockwave and Mach disk phenomena. Demonstrating supersonic air flow in the chamber is consistent with complementary CFD work. The results from the initial experiment alone are inconclusive to suggest which of the three suggested mixing mechanism hypotheses are dominating the air-fuel dynamics in the RSCE. However, one major conclusion of this work is the proof for the presence of shockwave phenomena which are atypical of conventional engines.
\end{abstract}

Keywords: internal combustion engine; thermal propulsion system; efficiency; emissions; atomisation; recuperated split cycle engine; air-fuel mixing

\section{Introduction}

Land transportation and distributed power generation have been dominated by the fossil fuelled internal combustion engine (ICE) for over a century. However, the climate emergency has promoted a rapid and dramatic switch to other propulsion technologies powered by renewable energy. This revolution in vehicle propulsion is complemented by advances in other areas of mobility, such as smart cities, inter-vehicle connectivity and accessibility solutions, that aim to both reduce the demand and energy consumed by the remaining transportation services. To date the focus of legislators has been on tailpipe emissions but in the future consideration of the full lifecycle impact of the manufacture, use and disposal of transportation vehicles, infrastructure and services will be necessary to achieve the net zero target and beyond.

Battery electric propulsion will dominate the passenger and light commercial vehicle sector, where short low energy consumption journeys are prevalent [1]. However, long distance, large payload, high energy applications and remotely operated machines, such as inter-city transport, haulage, off-highway, marine, and portable power generation, are much harder to electrify and other solutions are required that are also able to reduce emissions. Research has shown that freight transport may only make up to $20 \%$ of the 
distance travelled but account for $50 \%$ of the total energy consumption of road transport in Europe [1]. These applications still have the potential to be net zero carbon if they can utilise an engine that consumes a 'green' carbon neutral fuel. Such as synthetic hydrogen, bio or 'e-fuels' made from biological and waste sources, carbon dioxide $\left(\mathrm{CO}_{2}\right)$ captured from the atmosphere and renewable energy. However, there remains an issue around other emissions produced during combustion in an ICE apart from $\mathrm{CO}_{2}$. For an ICE to be truly zero emissions it must produce nitrous oxides $\left(\mathrm{NO}_{\mathrm{x}}\right)$, soot, hydrocarbons $(\mathrm{HC})$, carbon monoxide (CO), and other trace toxic emissions at levels below the World Health Organisation limits at the point of use. It should be noted that carbon neutral fuels are still in early-stage development and are currently expensive in terms of resource and energy use. With a present cost of approximately 3.5 times that of fossil fuels [2]. Therefore, ICE efficiency is still of importance for green fuels to have a shorter adoption timeframe and be a viable replacement for fossil fuels without a significant economic impact on society.

The thermodynamic cycles used in conventional ICEs (Diesel and Otto cycles) have not changed for over a century. ICE's have improved dramatically in terms of efficiency and emissions over this time, but this can mostly be attributed to reducing losses, improved air-fuel mixing, and combustion technologies, rather than a step improvement in the thermodynamic cycle itself. Atkinson cycles have been adopted in some recent vehicles, such as those by Toyota, as well as small gains through novel valve timings, high pressure injection systems, lean homogenous compression ignition and energy recuperation in modern engines. However, the basic Otto cycle is approaching the fundamental limits of the cycle and new novel cycles have shown interest and need. For example, through the UK Automotive Council's Thermal Propulsion System roadmap and the US SuperTruck programmes [3,4].

There remains an efficiency emissions coupling problem in conventional thermodynamic cycles. Increasing combustion temperature increases efficiency but also increases production of $\mathrm{NO}_{x}$. Emissions are not directly addressed in-cylinder in conventional ICEs unless a cool, lean strategy is adopted, such as low temperature combustion (LTC). LTC can be 'forced' on a conventional ICE in a limited section of the engine operating map but the control over the end of compression temperature, and therefore the start of combustion, in these engines makes such strategies difficult to implement effectively. Therefore, alternative thermodynamic cycles are required for a step improvement in efficiency and emissions.

This paper will explore the operating specifics of a novel engine architecture, namely the recuperated split cycle engine (RSCE), currently under development by the University of Brighton and Dolphin N2. Previously reported analysis has shown that the engine can realistically approach brake efficiencies of $60 \%$, which represents an almost $20 \%$ step improvement over current advanced heavy-duty Diesel engines [5]. Early research on the RSCE focused on achieving high efficiency but also demonstrated exceptionally low $\mathrm{NO}_{x}$ emissions $[6,7]$. This paper is focused on presenting hypotheses for how the RSCE delivers the in-cylinder conditions for ultra-low emissions, as well as the data that prompted the research and early-stage experimental results.

The research took a 'first principles' approach to investigating fuel air mixing and combustion dynamics in the engine. A combination of literature and early-stage data from the engine test bed and air flow rig experiments were used to develop a hypotheses for the in-cylinder processes. The air induction process in the RSCE is very different to conventional engines, with high upstream $(>2 \mathrm{MPa})$ and differential pressures across the inlet valves. The main experimental focus in this paper is to capture optically the phenomena around the poppet valve through Schlieren imaging, as limited optical data is available in the literature at these conditions.

In this paper, a brief introduction to the basic working principles of the cycle will be presented, followed by some recent published test bed results [8] to show the unusual emissions trade-offs observed. Part of these results have been previously published [8], but they are included in this piece of work in order to compare and explain the indicators that motivated the research into the air dynamics, atomisation and combustion system. A 
conceptual model of the fluid dynamic processes across the valves and in the combustion chamber is proposed, from which hypotheses are developed to explain the observed performance of the engine. Results from an optical study, relevant to the dynamics of air flow and therefore atomisation, are presented to support the proposed hypothesis. In this first initial experimental study, there is no fuel injection, with a focus on the airflow dynamics before increasing the complexity by introducing a fuel spray in the future.

\section{The Recuperated Split Cycle Engine}

\subsection{Basic Principles}

Split cycle engines (SCE) have been documented since the end of the 19th century, and several variations have been the subject of research in the last two decades [5-20]. In a SCE, the conventional strokes of a four-stroke cycle are split into two cylinders. With a cold compression cylinder conducting the induction and compression strokes, and a hot combustion cylinder conducting the combustion-expansion and exhaust strokes. A crossover pipe enables the compressed gas from the compression cylinder to transfer to the combustion cylinder to then mix with the fuel and combust. By splitting the strokes into separate cylinders, the cylinder temperatures, compression and expansion ratios, cylinder size, valve geometry and valve timing are all decoupled. This also enables each cylinder to be individually optimised for their respective processes.

The RSCE thermodynamically operates similarly to a recuperated Brayton cycle. Brayton proposed an ICE similar to SCEs in the 19th century, with the first patented Brayton cycle engine known as Brayton's Ready Motor [21]. The novelty of the RSCE, compared to other SCEs, is that the crossover pipe utilises a recuperator (a heat exchanger). Waste heat from the exhaust is recovered to heat the charge air after compression but pre-combustion, which has been shown to be more efficient than recovery post-combustion using a Rankine cycle [22]. This concept is referred to as Dry Thermopower. Currently two further variations exist of the RSCE: Wet Thermopower and Cryopower. Wet Thermopower utilises water injection as a coolant to achieve quasi-isothermal compression, increasing the efficiency potential. Past research by Coney et al. described thermodynamic advantages of such a system $[15,23,24]$. A schematic diagram of the concept RSCE accompanied with an entropy diagram is shown below in Figure 1.

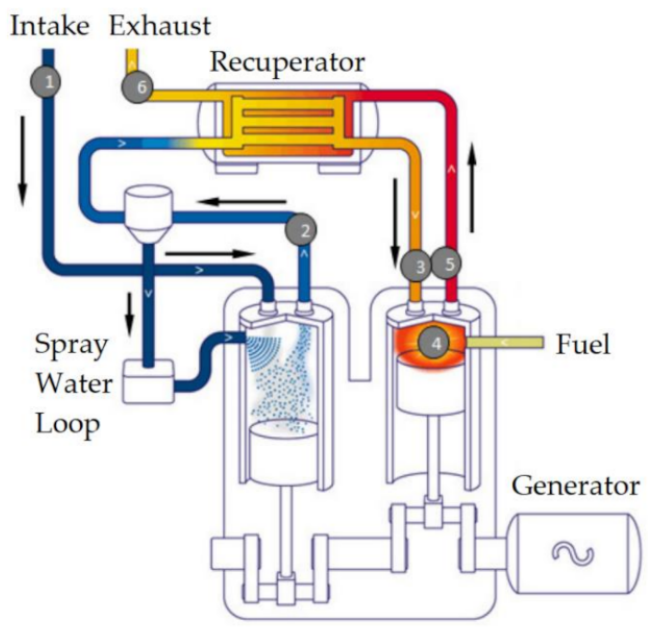

(a)

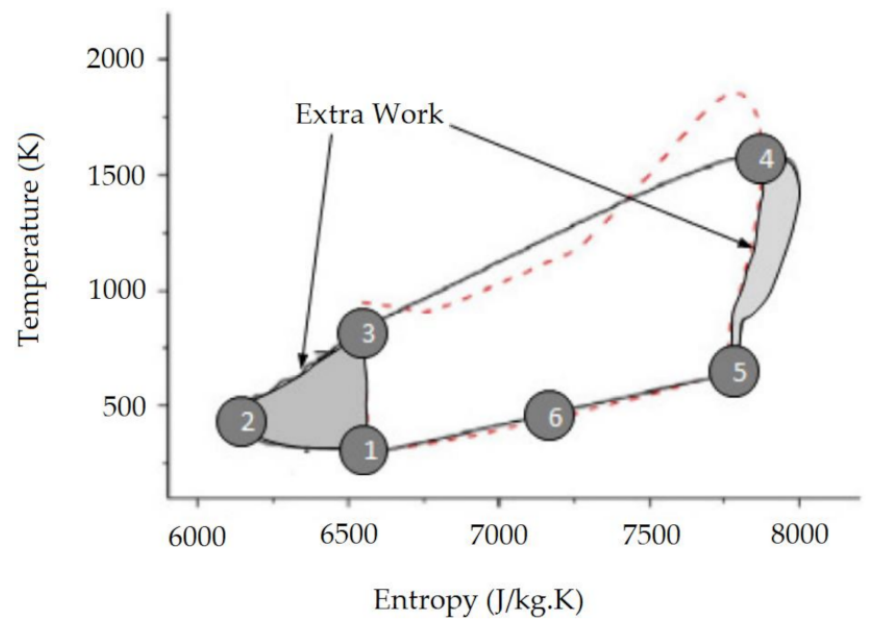

(b)

Figure 1. (a) Schematic diagram of RSCE concept; (b) Entropy diagram of RSCE (solid black line) compared to conventional Diesel (dashed red line), with extra areas of work highlighted in shaded grey areas. Numbers refer to positions in cycle in both diagrams (a) and (b) to aid comparison. Reprinted from Ref. [6] with permission. (c) SAE International.

The second variant, Cryopower further increases the efficiency potential towards $60 \%$ by utilising liquid nitrogen $\left(\mathrm{LN}_{2}\right)$ as the compression stage coolant $[5,25]$. This has a 
twofold effect on both efficiency and emissions. Efficiency is further increased as isothermal compression can be better realised compared to water cooling, due to the increased cooling potential of $\mathrm{LN}_{2}$ over ambient temperature water. $\mathrm{NO}_{x}$ emissions can also be reduced through LTC, as the adiabatic flame temperature is reduced with the dilution of air with $\mathrm{N}_{2}$, and phasing the combustion to predominantly occur after top dead centre (TDC). $\mathrm{LN}_{2}$ is cheap and readily available as it is a by-product of industrial gas production processes. $\mathrm{LN}_{2}$ can be easily produced from excess renewable energy, providing a clean energy vector and store which utilises primarily cheap and easily recyclable elements. Isothermal compression using $\mathrm{LN}_{2}$ will not be discussed further in this paper but is the subject of ongoing research $[25,26]$. Preliminary emissions results from the research combustion engine using air diluted with nitrogen are reported in past research [8], as well as detailed analysis of the RSCE thermodynamic cycle with isothermal compression $[8,17,18]$, and will not be discussed or investigated in this piece of work.

\subsection{Single Cylinder Combustion Research Engine}

The UoB hosts a single cylinder combustion research engine (SCCRE), which represents the combustion cylinder of the RSCE. The test bed parameters, thermodynamic and initial test data are reported in previous published research $[6,8,17,18]$. The SCCRE is based on a Ricardo Titan single cylinder research engine which has been modified and fitted with a hydraulic valve actuation system. The SCCRE differs from the full RSCE architecture in that compressed air is supplied by an air bank and the recuperator is fed with hot gas from a methane burner, rather than a compression cylinder and hot exhaust gas. This enables a high degree of independent control of key variables that affect the air dynamics and combustion processes in the engine. The fuel (Coryton reference diesel fuel) is supplied through a production Delphi common rail diesel injection system.

The temperatures at TDC occur over a similar range to a conventional Diesel ICEs, (700 to $1000 \mathrm{~K}$ compared with 800 to $1000 \mathrm{~K}$ ). However, the pressures are generally lower ( 2 to $7 \mathrm{MPa}$ compared to 6 to $12 \mathrm{MPa}$ ). In the RSCE the point of ignition is as much as 30 crank angle degrees (CAD) after TDC, where some cooling of the charge will have occurred through heat losses and expansion. LTC is achieved in the RSCE through controlled low initial combustion temperatures and comparatively late injection and valve phasing, to ensure expansion and combustion processes occur after TDC, thereby limiting the maximum temperature that the combustion gas can achieve during the combustion process.

\subsubsection{Comparison of RSCE with Conventional Diesel Engine}

In this section, selected experimental results will be reviewed and compared to illustrate the fundamental differences between the RSCE and a conventional ICE engine combustion system. The results are reported in detail in [8], but will be discussed here in more detail and compared to conventional a Diesel ICE to highlight the key questions regarding how the RSCE combustion system operates.

A comparison of three pressure traces can be seen in Figure 2, a comparison of PRR and ignition delay is also shown in Table 1. One pressure trace is that of a conventional Diesel cycle from a Ricardo Hydra single cylinder research engine at 2000 RPM, air fuel ratio (AFR) of 21 and $140 \mathrm{MPa}$ rail pressure. The two other pressure traces are from the SCCRE and are of differing intake pressures (3.85 MPa and 2.89 MPa) at 1200RPM, 21 AFR and $120 \mathrm{MPa}$ rail pressure. The valve events for the SCCRE are noted at the bottom of Figure 2, the valve events of the conventional Diesel pressure trace are not noted. All tests displayed in Figure 1 have the same start of injection (SOI) timing of -4 CAD. 


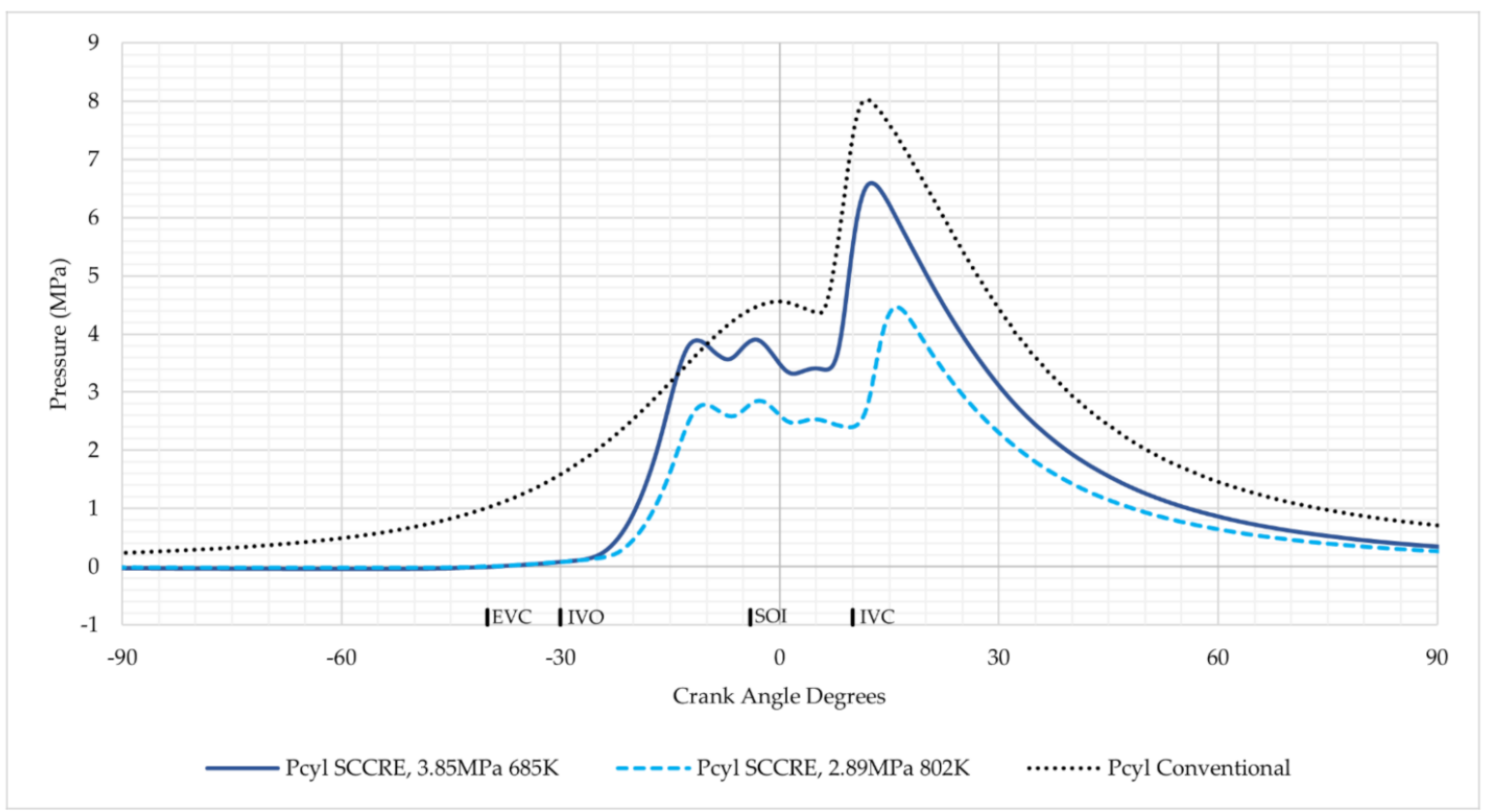

Figure 2. Comparison of three pressure traces. Two from the SCCRE at 1200 RPM and one from a conventional Diesel engine at 2000 RPM. All at 0.69 equivalence ratio (21 AFR). SCCRE data adapted from Ref. [8] with permission. (C) SAE International.

It can be seen in Figure 2 that the two pressure traces in the SCCRE do not resemble that of conventional Diesel or Otto ICEs pressure traces. There is a small increase in pressure at $-35 \mathrm{CAD}$ as a small amount of residuals from the previous cycle are compressed. Before a sudden large increase in pressure at intake valve opening (IVO) is recorded, as air is introduced into the chamber and equalises to the set inlet manifold pressure. Pressure equalisation occurs before the maximum valve lift of $3 \mathrm{~mm}$ is achieved. The intake valves close (IVC) after TDC when expansion is already underway and, depending on the case, combustion may already be occurring. A more detailed investigation of the air motion during these steps will be covered in Section 2.3.

Table 1. Comparison of maximum PRR and ignition delay of the three pressure traces presented in Figure 1.

\begin{tabular}{ccc}
\hline Pressure Trace & Maximum PRR (MPa/CAD) & Ignition Delay (CAD) \\
\hline SCCRE 3.85 MPa & 1.0 & 11 \\
SCCRE 2.89 MPa & 0.6 & 14 \\
Conventional Diesel & 1.0 & 9 \\
\hline
\end{tabular}

Comparing first the two SCCRE pressure traces: Both cases have identical valve timings, injection timings, operating at 1200 RPM, 120 MPa rail pressure and an AFR of 21. However, they differ in manifold pressure and intake temperature. As the methane burner that feeds the recuperator is at the same set temperature $(\sim 1080 \mathrm{~K})$ in both cases and the mass flow of air through the recuperator increased with pressure, this led to a variation in temperature between the two cases. The $3.85 \mathrm{MPa}$ intake pressure case has a decreased ignition delay of approximately $3 \mathrm{CAD}$ and increased PRR of $0.2 \mathrm{MPa} / \mathrm{CAD}$ compared to the lower $2.89 \mathrm{MPa}$ case. Both cases display a small increase in pressure around $3 \mathrm{CAD}$ with similar PRR. This is most likely the result of reflected pressure waves in the cylinder but could be a small initial heat release. This is followed by the main heat release, with an earlier and faster burn in the $3.85 \mathrm{MPa}$ intake manifold pressure test point.

Comparing the conventional Diesel and 3.85 MPa case: Both the 3.85 MPa SCCRE and conventional Diesel pressure traces have similar maximum PRR of approximately 1.0 MPa/CAD, with the 2.89 MPa displaying a slightly lower maximum PRR of 
0.8MPa/CAD. Similarly, the higher pressure SCCRE case and conventional Diesel differ marginally in ignition delay, with ignition delays of 11 CAD and 9 CAD, respectively. The lower pressure 2.89 MPa case displayed a longer ignition delay of 14 CAD. However, once the differences in RPM are considered, the Diesel pressure case demonstrates that the higher temperature and pressure in the conventional Diesel trace is resulting in almost 167\% increase in PRR. Both comparisons demonstrate that increased PRR, and therefore reactivity, is still primarily dictated by pressure and temperature conditions of the charge air.

Figure 3 presents a comparison of rail pressure swings from the SCCRE and a conventional Diesel single cylinder research engine (Ricardo Proteus). With the SCCRE operating at a speed of 1200 RPM, and 21 AFR, and the Ricardo Proteus operating at 1250 RPM and 22 AFR. Filter smoke number (FSN) was observed to plateau at a lower rail pressure condition of approximately $100 \mathrm{MPa}$ in the SCCRE, compared to the conventional Diesel engines rail pressures of approximately $180 \mathrm{MPa}$. $\mathrm{NO}_{x}$ emissions also increased with increased rail pressure in the case of the SCCRE, suggesting the dependence is still in line with that of conventional engines. This is expected in both scenarios, as with higher temperatures carbonaceous matter is more likely to combust and $\mathrm{NO}_{\mathrm{x}}$ is more likely to be produced. However, as rail pressure increases to very high pressures $(>100 \mathrm{MPa})$ it would be expected in conventional engines for $\mathrm{NO}_{x}$ to begin to flatten out. This would suggest that the local premixed air and fuel is close to stoichiometric, rather than rich local equivalence ratio in Diesel engines.

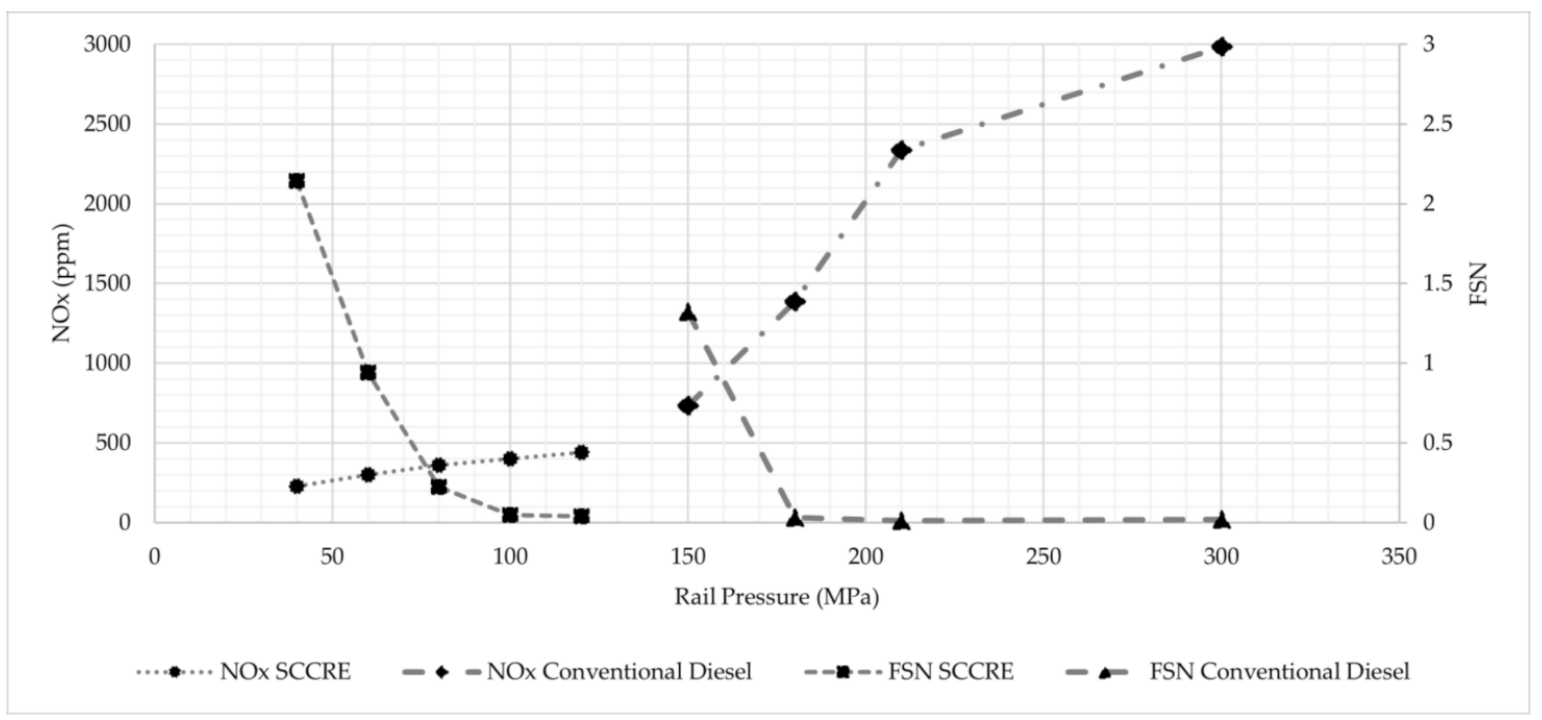

Figure 3. NOx and FSN vs. rail pressure from the SCCRE at 1200 RPM and 0.69 equivalence ratio (21 AFR) and from the Proteus at 1250 RPM and 0.66 equivalence ratio (22 AFR). SCCRE data adapted from Ref. [8] with permission. (C) SAE International.

The earlier plateauing of FSN with rail pressure, increasing $\mathrm{NO}_{x}$ with rail pressure and high PRR (relative to the low temperature and pressure conditions), suggests there is an amplified or new phenomenon enhancing the air fuel mixing before combustion in comparison to conventional Diesel combustion systems. The two sets of data suggest that mixing has been amplified while reactivity has declined. The decline in reactivity can be attributed to the lower peak pressures and temperatures, however the increased mixing warrants further investigation.

\subsection{Conceptual Air Transfer Process}

The transfer of the charge air from the inlet port to the combustion chamber in a RSCE is a very different process to that in a conventional ICE. In a conventional engine, 
the expanding volume of the combustion chamber during the induction stroke draws air into the combustion chamber. In the RSCE, the air is 'injected' due to the high-pressure difference upstream and downstream of the combustion cylinder intake valves. This creates a unique air injection event in SCEs not typically found in reciprocating ICEs.

Air assisted fuel injectors have been mooted in the past [27-34]. In these studies, air assisted atomisation displayed promise for enhancing fuel atomisation, but adoption of air assisted atomisation in a conventional ICE architecture has so far been deemed prohibitive by manufacturers, possibly due to the potential gain versus the complexity and cost of adding and operating an auxiliary high pressure air system. The RSCE architecture lends itself to a form of high-pressure air assisted fuel atomisation, as a high-pressure working fluid source is readily available. However, the case in the RSCE differs from the air assisted atomisation literature [27-34], as the chamber pressure is low at the start of the air and fuel injection, and the air is heated by exhaust gas. This enables a higher-pressure difference than performed in the assist air literature to date and creates a lag in temperature equalisation, as the air expands and then compresses downstream of the poppet valves. Theories and hypotheses on the dynamics of this process will be described in Section 3.

At the start of IVO, the pressure difference across the intake valves in the RSCE is up to 7.0MPa, varying depending on load conditions. These high differential pressures can create a choked flow at IVO which continues until the pressure ratio between the chamber and manifold is below 1.893 for dry air, a simple illustration of this is presented in Figure 4 . The choked flow initially limits the mass flow into the combustion chamber, causing it to accelerate to supersonic speeds after the poppet valve constriction and display supersonic phenomena, such as shocks. As the air pressure equalises between the upstream and downstream conditions after IVO, the flow is no longer choked as the pressure ratio lowers. This occurs approximately over 5 to 10 CAD, depending on IVO and EVC timings and intake manifold pressure. This causes the air to experience a large expansion initially at IVO followed by a compression, as the air pressure equalises between the manifold and the combustion chamber. Therefore, there is a large variation in the state, density, and temperature of the air in the chamber as it first expands and then compresses during the air injection and pressure equalisation events.

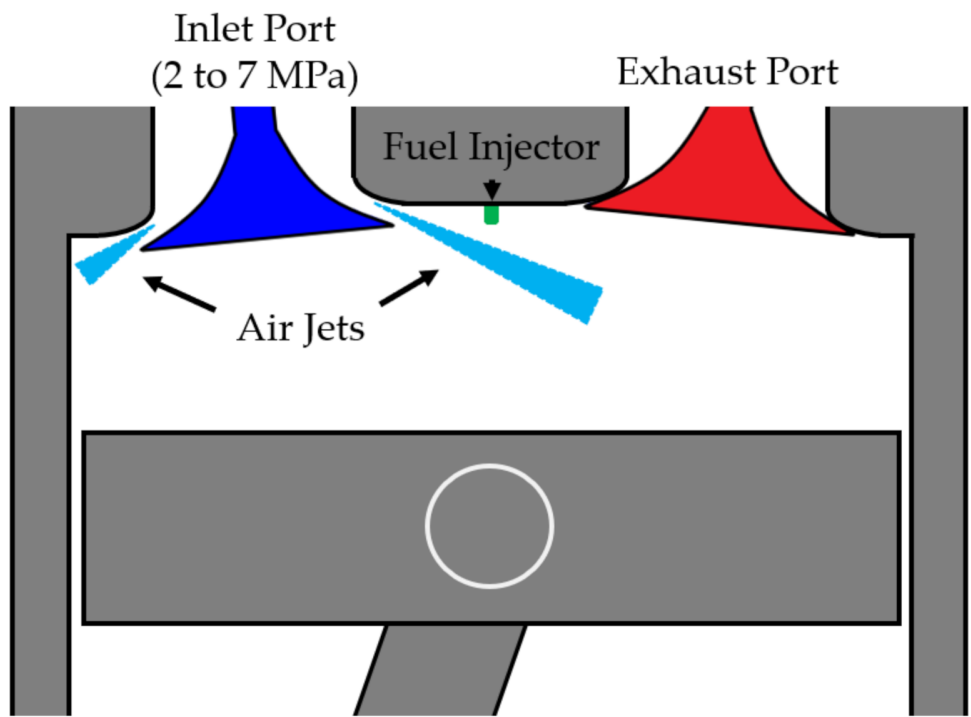

Figure 4. Simple 2D diagram of combustion chamber with inlet air jets in SCCRE.

It is difficult and computationally expensive to model the full conditions in the RSCE, due to the potential supersonic and/or supercritical conditions prevailing the air flow dynamics, moving geometry, fuel injection and combustion dynamics. For this reason, CFD studies to date have been simplified, utilising steady upstream flow conditions, static 
geometries and/or 2D models $[35,36]$. For the same reasons, an experimental approach was taken using test rigs to investigate and describe the induction event in the engine. Previous CFD studies indicated that the injected air is at supersonic conditions at the beginning of IVO and predicted high turbulent kinetic energy in the combustion chamber [35]. Air velocities were predicted to be 150 to $500 \mathrm{~m} / \mathrm{s}$ [35] compared to the 10 to $30 \mathrm{~m} / \mathrm{s}$ typically observed in conventional ICEs. This creates unique flow dynamics across the whole chamber but specifically around the inlet valves, close to the injection point and on the cylinder walls.

\section{Underlying Principles \& Hypotheses for the Air Fuel Mixing Mechanism}

It is proposed the atomisation and combustion processes in the SCCRE, and therefore the RSCE, are primarily driven by the unique air dynamics. This is thought to causes the air fuel mixture to have a high amount of premix (regardless of the direct injection of the fuel) before combustion, giving rise to low emissions and rapid mixing of the fuel producing the PRR, $\mathrm{NO}_{x}$ and FSN responses presented in Section 2.2.1. The exact physical phenomena that have cause this increased mixing are unknown. From analysis of test bed data and the literature relevant to various jet dynamics, three hypotheses are proposed here that alone or in combination could contribute to the enhanced mixing observed.

Hypothesis 1. Increased Mixing Driven by Increased Charge Air Bulk Velocity, Swirl E Turbulences.

Atomisation and combustion dynamics in modern diesel fuelled engines are primarily driven by high fuel injection pressures and low swirl ratios $(<2)$. Mixing is largely driven by high injection pressures, usually in excess of $200 \mathrm{MPa}$ with some systems approaching $400 \mathrm{MPa}$ [37], promoting atomisation of the fuel jet and mixing with the charge air. Bulk structured air motion via swirl contributes to air-fuel mixing but to a lesser degree than that of the high injection pressure of the liquid fuel spray.

It is proposed that in the case of the RSCE the opposite is true, leading to fuel injection pressures of $100 \mathrm{MPa}$ being sufficient. With high air velocities from injection of air into the combustion chamber resulting in large scale flow structures and higher turbulence, directly affecting the Weber number and thus the atomisation processes. The high-pressure ratios, of up to 70 to 1 , between the inlet duct and combustion chamber will cause higher air velocities and could induce swirl or tumble like motion in the combustion chamber.

Enhancing swirl has been shown to decrease ignition delay and combustion duration but typically incurs higher pumping losses in Diesel ICE [38]. In the Aumet Z engine, another SCE variant, novel valves were utilised to generate air flow conditions with high swirl ratios (20-40), high velocities $\left(>100 \mathrm{~ms}^{-1}\right)$ and low $\mathrm{NO}_{\mathbf{x}}$ emissions reported $[39,40]$. This suggests similar inlet air driven mixing could be occurring in the SCCRE.

It is proposed the high velocities induced during air induction in a RSCE result in residual air motion still present at the start of injection of the fuel. This promotes enhanced mixing before ignition and a high fraction of the fuel reacts from a lean dilute mixture resulting in low $\mathrm{NO}_{x}$ emissions and a high rate of heat release.

Lean premixed combustion in swirling flames has shown potential to reduce $\mathrm{NO}_{\mathrm{x}}$ emissions in non-engine experiments, resulting in a blue 'cool' flame [41,42]. Characterisation of these diffusive flames have been performed on methane and hydrogen low swirl burners but there is little experimental literature characterising blue 'cool' swirling flames with a Diesel fuel [38,41,42]. The small initial PRR after TDC, discussed in Section 2.2.1, could be an indication of blue 'cool' flame kinetics before the main autoignition, due to a lean to stoichiometric local equivalency ratio air fuel mixture, high swirl, and turbulence in the chamber. However, further research is needed before this can be said with any certainty.

Hypothesis 2. Increased Mixing Driven by Impinging Jet, Airblast \& Crossflow Atomisation.

The very high-pressure ratios create inlet air conditions that are expected to be closer to that of a rocket injector than that of a conventional ICE. This creates a curtain jet of air past the constriction of the poppet valves of high density and velocity air, which would 
only occur when the air flow through the valve is choked, i.e., above the minimum pressure ratio (1.893 for dry air). The fuel injector is located centrally, and the fuel spray injects into the area where this air jet curtain would materialise. Potentially producing impinging, crossflow, or transverse jet atomisation effects, as the fuel jet interacts with this high velocity air flow field. A simple diagram showing how these two flows may interact is shown in Figure 5.

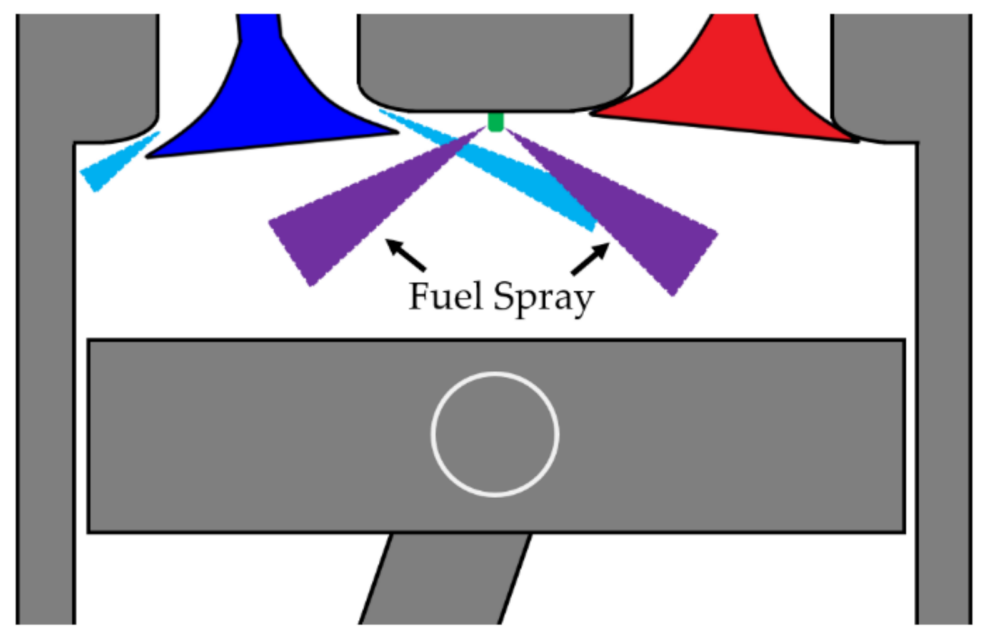

Figure 5. Simple 2D diagram of combustion chamber with fuel and air jets in SCCRE.

Impinging jet atomisation has been shown to produce rapid atomisation of the fuel spray but has typically focussed on liquid nitrogen and/or liquid oxygen mixtures at sub to supercritical conditions into sub to supercritical environments [43]. It is proposed that if the air jet is still present at the start of injection, the interaction of the two jets would promote rapid breakup of the fuel spray, mixing and combustion.

As mentioned in the Section 2.3, there is little literature on air assisted atomisation in ICEs and typically they have been at low air injection pressures $(<1.0 \mathrm{MPa})$. Air blast atomisation and crossflow atomisation at high pressures ( $>1.0 \mathrm{MPa}$ ) have seen wider experimentation in literature associated with applications such as rockets, ramjet, scramjet, and gas turbine combustors [44-50]. Generally higher pressure and velocity conditions have demonstrated enhanced mixing, with high velocity subsonic and supersonic crossflow conditions producing rapid mixing in comparison to coaxial jet injection [44]. Both primarily utilised relative velocity and density as a route to increased mixing. However, as the high-pressure research has typically been focussed on rocket and ramjet applications, the experiments involved an open volume and have had difficulties in combustion stability and performance in the past, with the physiochemical mechanisms at supersonic conditions still not well understood [50].

The conditions in the RSCE differ from that of other comparable high-pressure impinging jet literature, as a liquid diesel fuel spray is injected into a high-pressure gaseous air jet [43]. By virtue of being in a reciprocating engine the air flow field is further complicated by the chamber volume compressing and expanding. At certain conditions and areas, the air may also be in a supercritical state.

\section{Hypothesis 3. Increased Mixing Driven by Pressure \& Shock Waves.}

As discussed in the previous section, at certain locations in the cylinder the flow field (most notably around the intake valves) the air may be supersonic and induce shockwaves, at least initially at IVO and while the pressure ratio is exceeded. These pressure waves could reflect off in-cylinder surfaces, superimpose, and affect the fuel breakup as they interface with the fuel spray. Chehroudi et al. demonstrated that acoustic waves can affect jet breakup substantially, depending on the initial conditions of the fluid and chamber [51]. 
The research [51] utilised cryogenic nitrogen, injecting into chambers of 1.46-4.86 MPa and pressure ratios of $0.43-1.43$, with the acoustic wave induced by an oscillator at the injector at 161 to $171 \mathrm{db}$ and two set frequencies of 2700 and $4800 \mathrm{~Hz}$. Research has also shown that lower temperatures enhance shockwave propagation while higher densities inhibit this. Shockwaves have been shown to be induced by the fuel injector at low enough temperatures and charge air densities by Kook et al. [52]. These could in theory propagate to a higher extent in the SCCRE and RSCE due to the lower temperatures and charge air densities. However, the shockwave induced by the injector will be of a lower magnitude than that of shockwave generated by that of the inlet valves. Other works have been produced studying shockwaves generated by the spray and the effect this has on spray penetration [53]. However, there is no research on the effect of sprays interacting with shockwaves or reflected waves generated from another source in a closed volume.

It is hypothesised that the choked flow conditions are enabling pressure and shock waves to form and enhance the breakup of the fuel spray in the SCCRE, as the spray interfaces with these induced reflected pressure waves in the cylinder. Forcing the spray and/or droplets to increase mixing due to the pulsating translational movement caused by these waves.

\section{Of Note: Diffusive Mixing.}

After the primary jet breakup, that is mostly driven by Kelvin Helmholtz instabilities based on stripping of the potential core, diffusive mixing may become an important contributing factor in the secondary breakup of the liquid fuel, instead of 'catastrophic breakup' based on Rayleigh Taylor instabilities common in diesel jets. Diffusive, transcritical and supercritical mixing has been shown to occur above supercritical pressure conditions in impinging jet atomisation experiments involving gaseous-gaseous interfaces $[43,54,55]$. Research by Manin et al. [56] has shown that injection conditions need to exceed that of the critical conditions of diesel $(618 \mathrm{~K}, 2.1 \mathrm{MPa}$ for decane) and air $(133 \mathrm{~K}, 3.8 \mathrm{MPa})$ to exhibit transcritical or supercritical diffusive mixing phenomena while utilising a liquid diesel fuel. Surface tension forces were shown to diminish at these elevated conditions. If ligaments and droplets are already of a smaller size after the first stage of mixing, due to one of the hypotheses increasing atomisation, diffusive mixing could promote further rapid mixing in the second stage of atomisation that is not typically seen in conventional Diesel engines at low chamber pressures and temperatures $(<133 \mathrm{~K},<3.8 \mathrm{MPa})$.

\section{Schlieren Flow Rig Experiments}

In the previous section three hypotheses were proposed that could be improving the mixing and combustion in the SCCRE. The hypotheses were formed purely on the operating conditions and evidence in the literature. In this section a test programme performed in collaboration with the Sheffield Advanced Manufacturing Research Centre (AMRC) will be described. The test programme was performed to optically capture the flow around the valve in order to study the processes taking place and validate the hypotheses. The collected data can help visualise the phenomena taking place through the air-fuel interaction in the RSCE and thus begin unpicking which of the phenomena described in the previous section are dominant and which are secondary. The flow rig replicates the valve geometry of the SCCRE, with no fuel injection or combustion, and static positions of valves. Several tests were conducted with varying valve lift and high-pressure conditions captured optically using a Z Schlieren setup. The optical work focussed on the near field flow around the valve seat at IVO. This was of interest to better understand the flow field that is created by the unique choked flow conditions around the poppet valve in the SCCRE. In the SCCRE the maximum valve lift is $3 \mathrm{~mm}$ and pressure equalisation between the combustion chamber and the inlet manifold occurs before full valve lift is achieved. For this reason, this initial study will concentrate on valve lifts at $1 \mathrm{~mm}$ and under. As there is no fuel injection and an open volume is used in this experiment, the effects these 
conditions have on the fuel spray and the effect of pressurisation cannot be ascertained from this first initial experiment alone.

In the experiment high pressure tanks are filled with air before discharging through a regulator at a set pressure to a digital control valve. Before then passing through an air mass flow meter to the cylinder head. After passing through the head and past the valves, the air is discharged to atmosphere through a muffler. This does not capture any possible flow interactions and reflections that will occur in a closed volume with a piston. The air jet curtain and mass flow were the main source of interest in this initial test. Optical access is below the head with two flat windows either side for imaging. Figures $6-8$ illustrate the experimental setup.

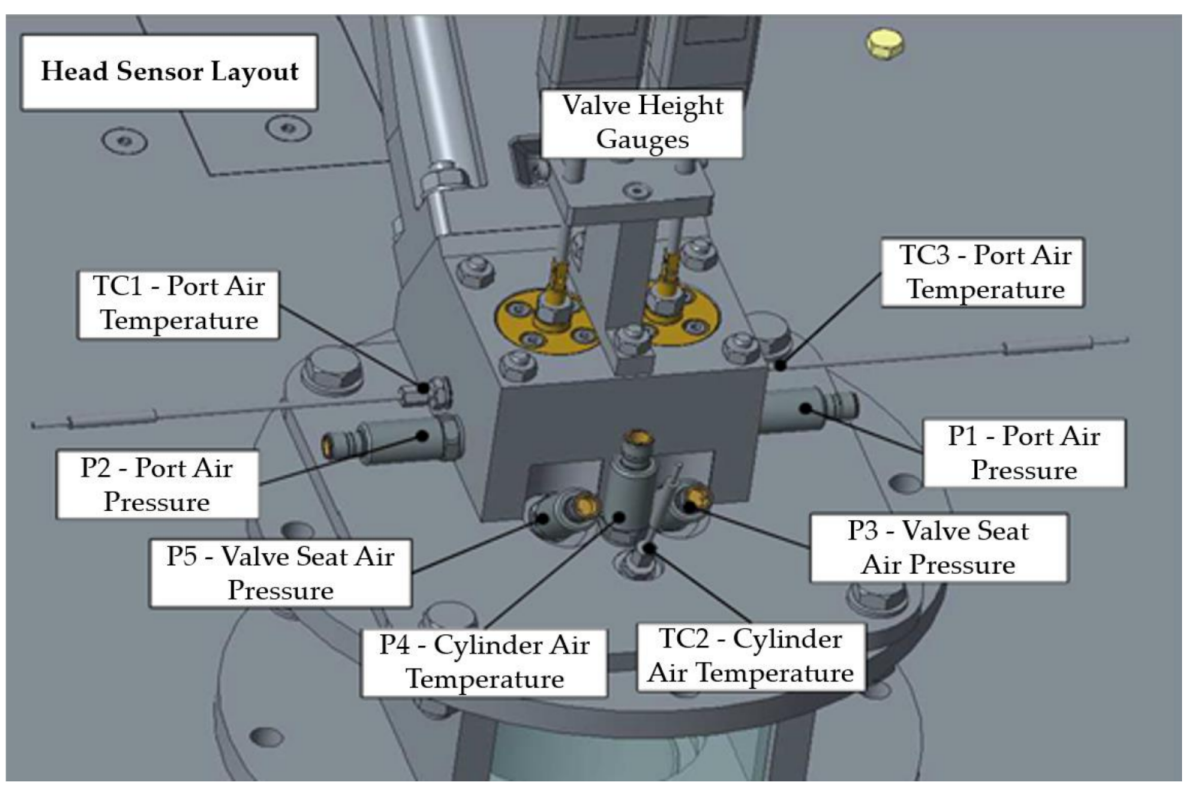

Figure 6. ARMC flow rig head sensor layout.

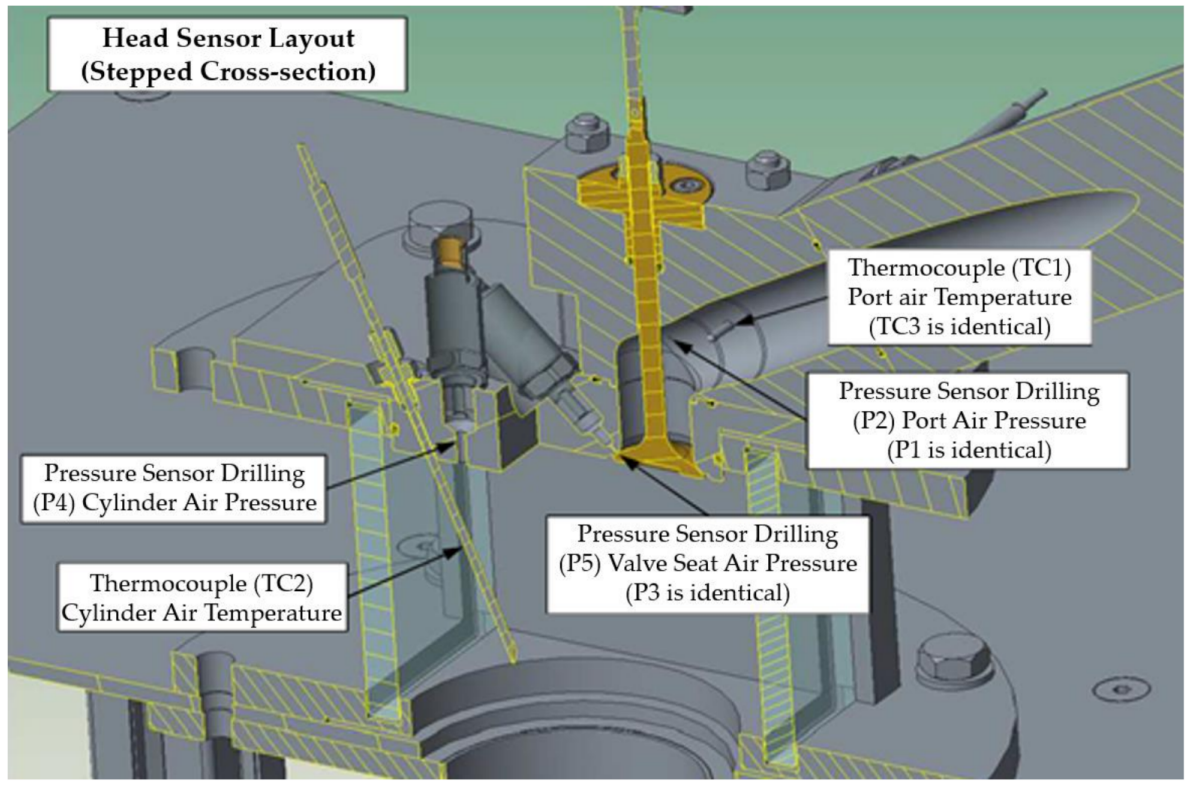

Figure 7. AMRC flow rig head sensor layout (stepped cross-section). 


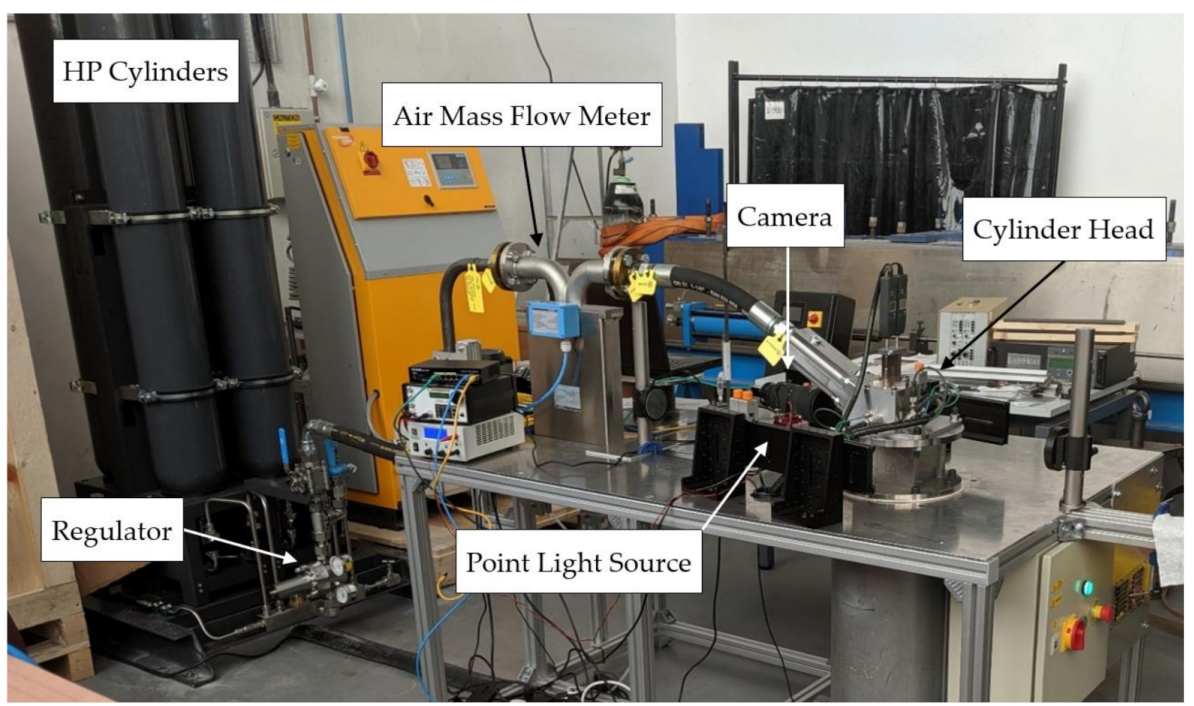

Figure 8. Overview of AMRC flow rig experiment setup.

A range of pressures from 1.5 $\mathrm{MPa}$ to $8.0 \mathrm{MPa}$ are tested at $1 \mathrm{~mm}$ valve lift, with a further small number of tests at the maximum regulator pressure $(8.0 \mathrm{MPa})$ and decreasing valves lift, as well as number of valves open. The test schedule is shown in Table 2.

Table 2. AMRC flow rig test schedule.

\begin{tabular}{cccc}
\hline Test & Valves Open & Lift $(\mathbf{m m})$ & Regulator Pressure (MPa) \\
\hline 1 & 2 & 1.0 & 1.5 \\
2 & 2 & 1.0 & 1.5 \\
3 & 2 & 1.0 & 2.5 \\
4 & 2 & 1.0 & 2.5 \\
5 & 2 & 1.0 & 2.5 \\
6 & 2 & 1.0 & 5.0 \\
7 & 2 & 1.0 & 8.0 \\
8 & 2 & 0.5 & 8.0 \\
9 & 2 & 0.2 & 8.0 \\
10 & 1 & 0.2 & 8.0 \\
11 & 1 & 0.1 & 8.0 \\
12 & 1 & 0.1 & 8.0 \\
\hline
\end{tabular}

There is an expected drop in pressure between the regulator and the port, primarily due to the mass flow meter, but generally the pressure is consistent over the first $2 \mathrm{~s}$ of the experiments for all test cases. There is a sudden increase in mass flow around 0.6-0.7 s as an extra amount of air mass is needed to pressurise the column of air between the cylinder head and the regulator. Over the $1 \mathrm{~mm}$ valve lift tests there is an expected larger increase of mass flow rate with pressure, as a larger amount of mass is required to bring the volume between the regulator and the valves up to higher pressure.

At the higher-pressure test conditions, it was noted from the optical work that the valve stem was beginning to stretch by a large amount relative to the amount of lift that was set. This was most notable at the highest regulator pressure of $8.0 \mathrm{MPa}$ and the sub $1 \mathrm{~mm}$ valve conditions. For this reason, the valve lift was corrected to account for stretch of the stem before the velocity is deduced through the conservation of mass equation. The limited temperature measurement of the port adds error to the calculation of density at the constriction, but still yielded useful results. The velocity through the constriction without the correction for valve stem stretch is shown in Figure 9. Figure 10 incorporates the correction for valve stem stretch. Within a margin of tolerance for noise, the cases with $1 \mathrm{~mm}$ valve lift (Tests 1-7) displayed velocities of $\sim 46 \mathrm{~ms}^{-1}$. As expected and shown in 
Figure 9, at lower valve lifts the velocity through the valve constriction increased with the same upstream pressure and temperature conditions.

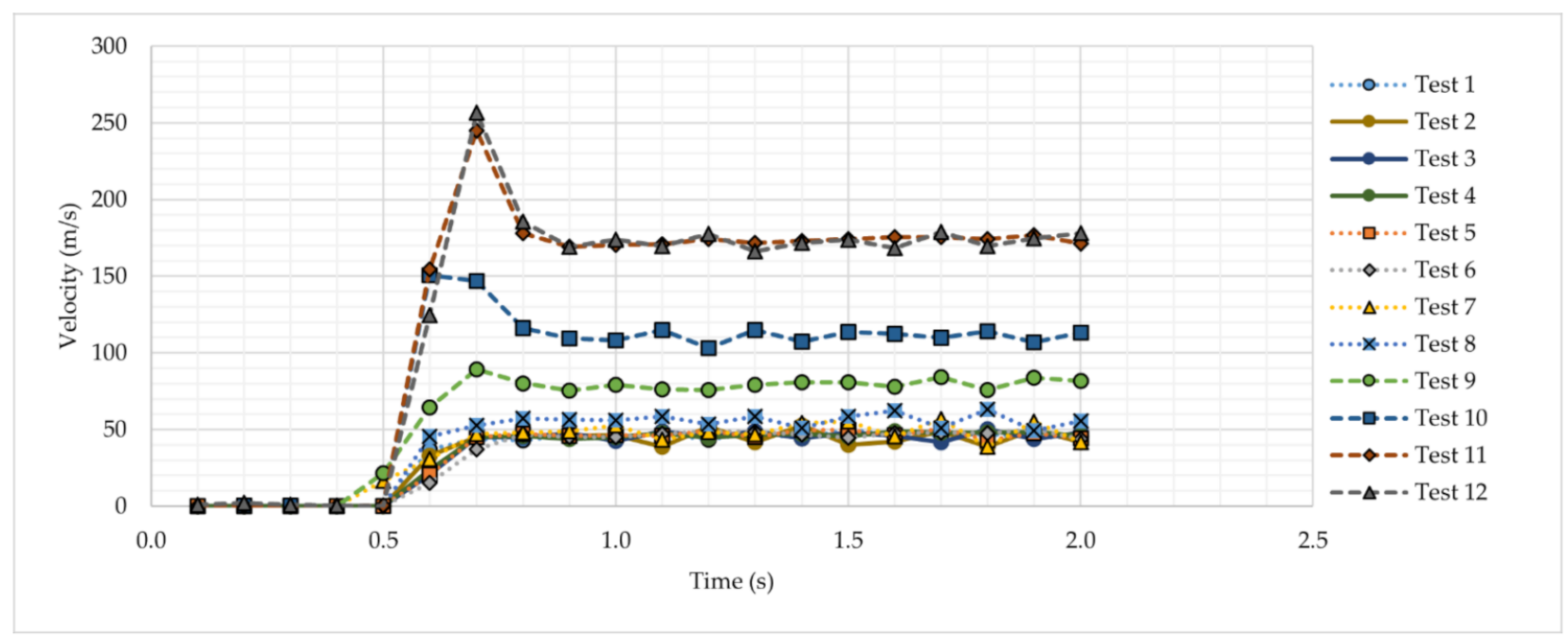

Figure 9. Calculated velocity through valve constriction using conservation of mass, uncorrected for valve lift extension.

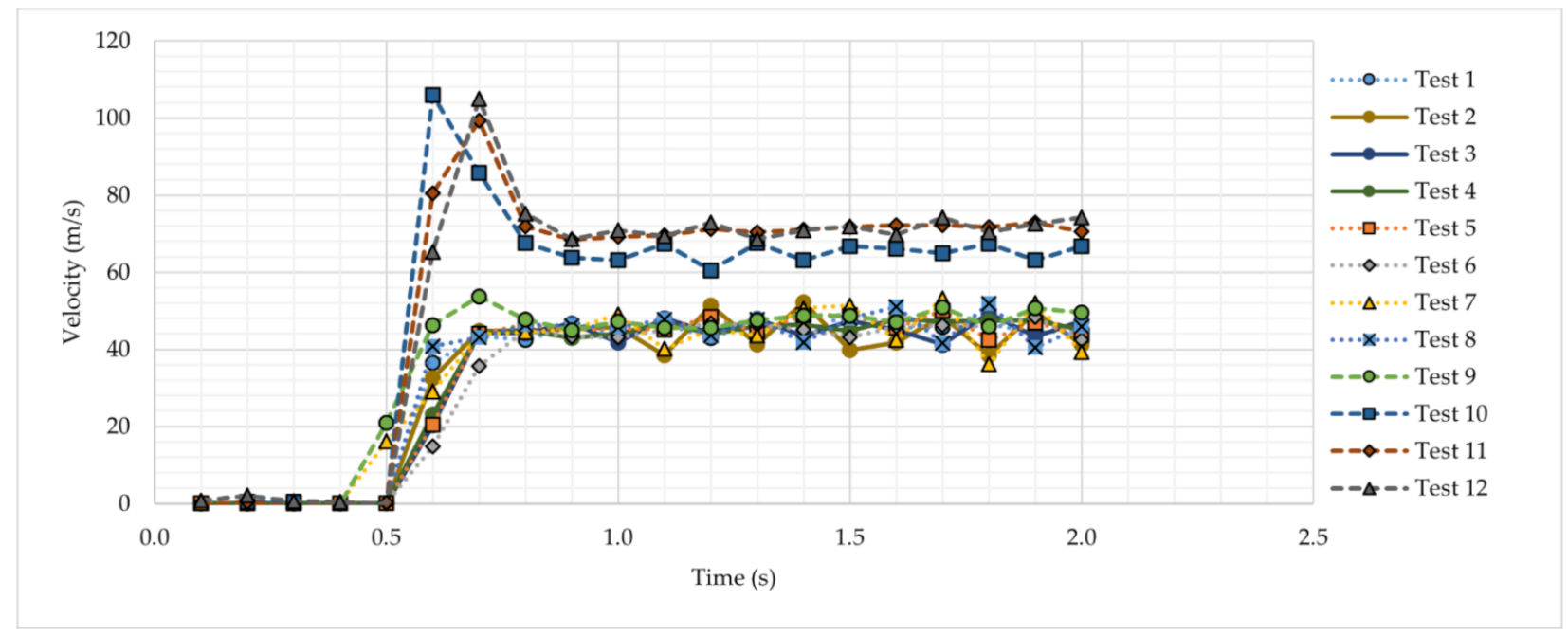

Figure 10. Calculated velocity through valve constriction using conservation of mass, corrected for valve lift extension.

Figure 11 shows a Schlieren image of the air injection taken at 5.0 MPa initial manifold pressure and $1 \mathrm{~mm}$ valve lift, conditions representative of initial valve opening and a third of maximum valve lift in the SCCRE. The optical focus in this setup is the edge of the valve seat. The resulting images suggest shockwaves are formed in the cylinder, supporting past CFD work that the flow field is at least partially trans/supersonic and could be enhancing atomisation processes, and flow rig data demonstrating the flow to be choked $[35,36]$. The image shows the flow field to be complex and potentially highly turbulent around and below the intake valve constriction. Two bow shocks in front of the valve seat and a separate recess around the valves are observed. Downstream of the valves into the valve 'curtain' Mach disks appear to form downstream of the bow shocks. Other poppet valve investigations have shown similar flow fields produced at elevated pressures and relatively low lift conditions [57]. Finding this flow field in a conventional ICE cylinder head utilising air or other working fluid is unique to SCEs. 


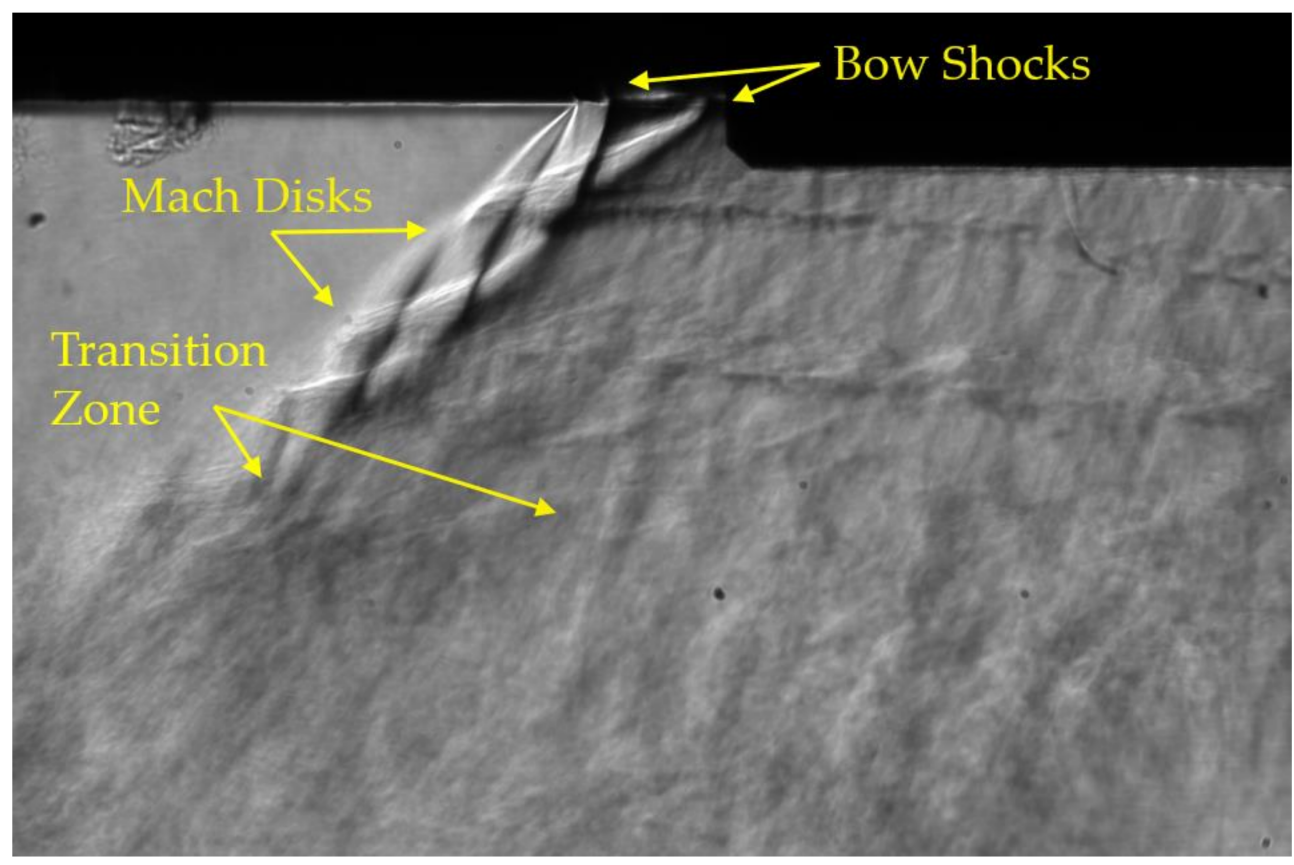

Figure 11. Schlieren of air jet 'curtain' created around poppet valve in first optical setup, at $5.0 \mathrm{MPa}$ and $1 \mathrm{~mm}$ valve lift.

It is worth reminding that Mach disks are complex flow field structures made visible by abrupt changes in local density and pressure as the (typically supersonic) air passes through a series of standing shock waves and expansion fans. They typically appear when the static pressure of the air exiting a nozzle is less than the ambient pressure. The higher ambient pressure will then compress the flow, and if the resulting pressure increase in the air downstream is adiabatic, the reduction in velocity will also cause the static temperature to be increased. The pattern of disks would repeat indefinitely if the gases were ideal and frictionless. However, phenomena such as turbulent shear causes the wave pattern to fade with distance.

The focus of the image presented in Figure 12 is slightly offset of the centre line of the chamber and just below the valves. This area was chosen to enable examination of the interface of the shocks from each valve, as well as the transition zone beneath them. The initial manifold pressure and valve lift were set at $5.0 \mathrm{MPa}$ and $1 \mathrm{~mm}$ valve lift, the same conditions as Figure 11. At these conditions, the structured flow diminishes approximately $5 \mathrm{~mm}$ directly below the valves and the transition zone begins. However, the interface of the shocks created an almost completely vertical turbulent shock or possible Mach disks from the superimposed shocks.

Although the Schlieren results cannot be used to quantitively assess velocity, directions of flow and between that of the current initial experiment and a previous CFD case can be compared. Firmansyah et al. produced RANS results in Figure 13 [35] which was annotated by the author to display the areas optically captured in Figures 11 and 12. The CFD case ran at $2.5 \mathrm{MPa}$ but as velocity is choked through the constriction the velocity is unchanged, enabling the cases to be compared. While the manifold pressures are not the same and the exact low valve lift in the CFD case is unknown, there is a generally good agreement in terms of flow direction between the simulation case and the optical experiments. However, the ANSYS RANS simulation is unable to pick up shocks and the high and low-pressure regions they create through the flow. 


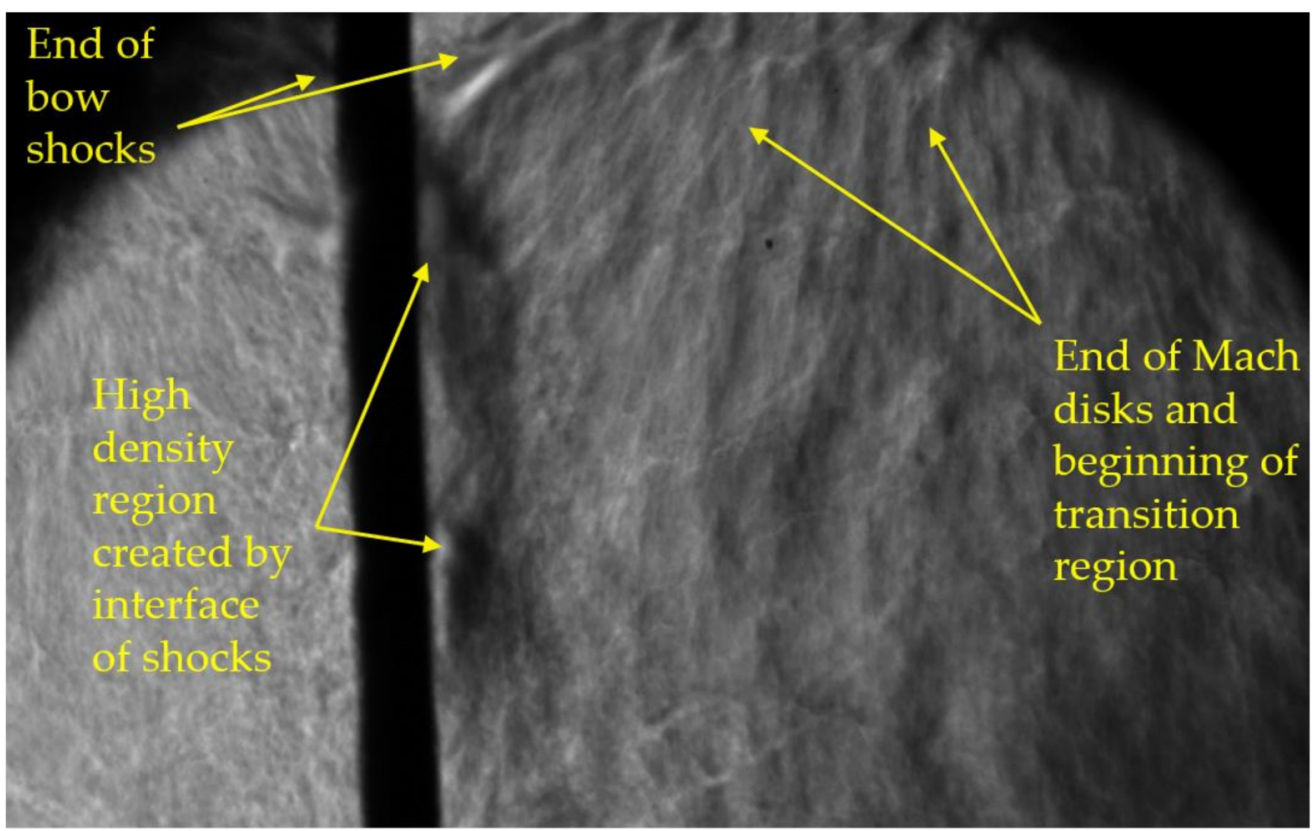

Figure 12. Schlieren of combining air jet 'curtains' below the poppet valves, slightly off center of the centrally mounted thermocouple, in the second optical setup, at $5.0 \mathrm{MPa}$ and $1 \mathrm{~mm}$ valve lift.

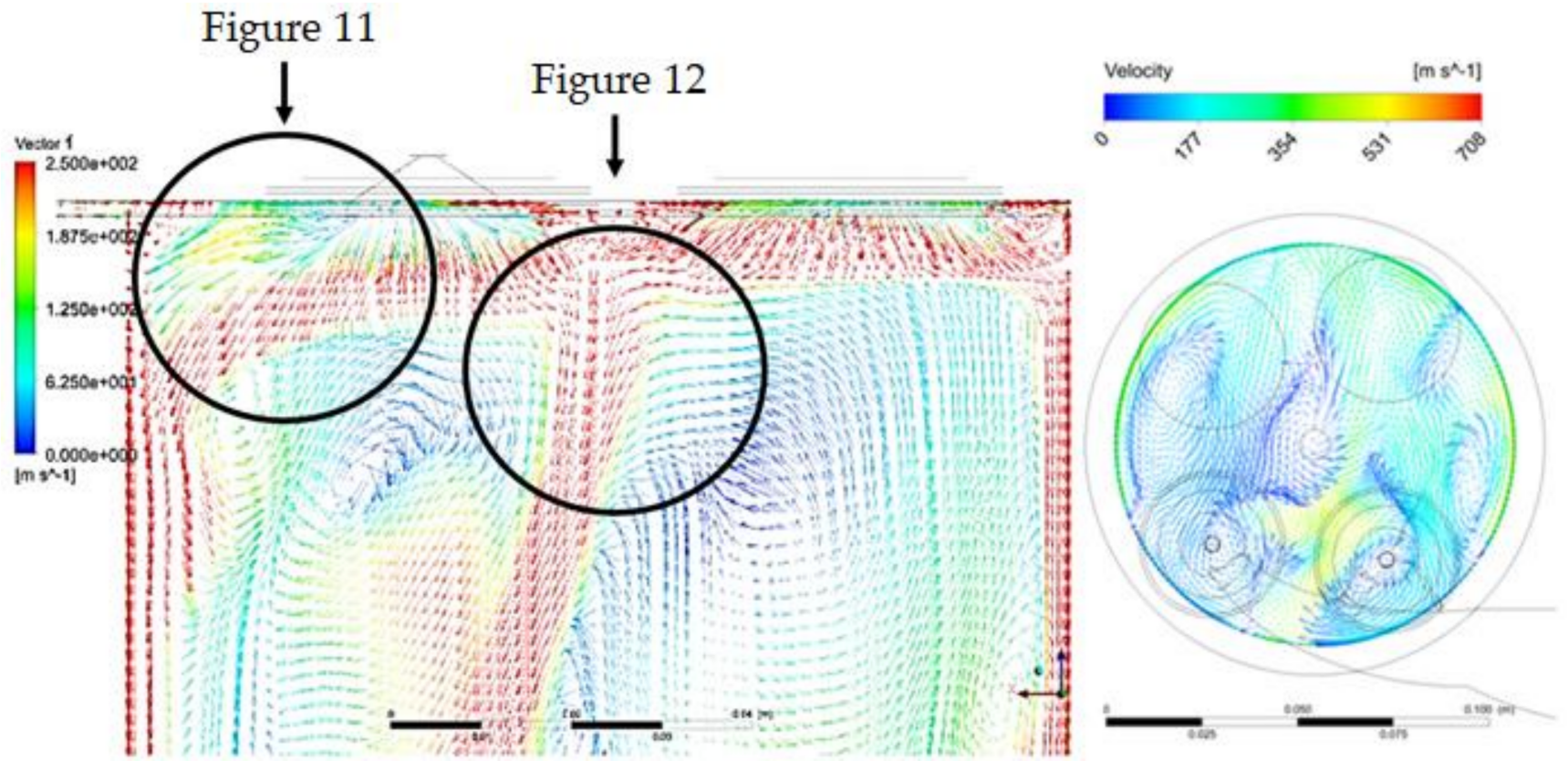

Figure 13. Annotated comparison of RANS CFD work by Firmansyah et al. [34] with the two the areas of focus in the Schlieren optical setups, at $2.5 \mathrm{MPa}$ and low valve lift, presented in Figures 11 and 12. Reproduced from [34], with the permission of AIP Publishing.

\section{Discussion}

It is proposed the unique inlet valve conditions, compared to conventional ICEs, play a significant role in the atomisation, chemical interactions, and combustion present in the SCCRE and RSCE. It can be said with certainty that the conditions in the chamber after pressure equalisation will be of considerable velocity, as demonstrated in past CFD work and Schlieren images. The choked flow caused by the high-pressure gradient will have 
a profound effect on the velocity and direction of the flow field. Even after the pressure gradient is lower than that required of choked flow conditions. While the exact speed of the flow field cannot be deduced from these Schlieren imaging presented in this work, the bow shocks confirm that the flow is at least locally supersonic in velocity. This has fair agreement with past CFD studies performed by Firmansyah et al. [35]. The increased turbulent kinetic energy created by this flow field in the combustion chamber must play a significant role in the increased mixing observed.

The geometry of the intake valves, specifically the valve seat, will have a substantial effect on the air flow, formation of shockwaves and air-fuel dynamics in-cylinder. The initial experiment presented in this work utilised standard poppet valves of modern ICEs, but this is clearly unoptimised for choked flow conditions, production of shockwaves or the impingement of air-fuel jets. This leaves further room for positive improvements through valve geometry to the dynamics of the air-fuel mixing in the future.

As the fuel injector is centrally mounted in the SCCRE, it is expected that the fuel spray from the injector experiences the highly complex flow regime captured in the Schlieren imaging reported in Section 4 and could impinge with the fuel spray. Whether or not the fuel spray and air jet impinge will depend on the injection and intake valve strategy. Previous work has shown the low emissions observed to occur over a range of injection timings [8] suggesting that hypothesis 1 is currently the dominant air-dynamic process taking place in the engine. If this is the case, there remains a large untapped potential to increase the air-fuel mixing further through novel air-fuel injectors aimed at creating impinging conditions and/or amplifying shock wave conditions.

As shockwaves are most certainly created in the combustion cylinder, they must also contribute to the turbulent kinetic energy in the flow field, but they will most likely not be as pronounced as the turbulent kinetic energy created by the high velocity and swirl. Shockwaves may or may not be interacting with the fuel spray, as the spray's persistence in the flow field may be limited due to the moving geometry, temperature, density conditions and intake valve and injection strategies.

Several of the mixing related hypothesised phenomena that are discussed in this piece of work will be present in the combustion cylinder, and other effects specifically related to combustion may be increasing the mixing and combustion rate observed in the initial motivational data from the test bed. The AMRC flow rig data confirms choked flow to be present with the difference in pressures involved. The optical data confirms the presence of shocks in the flow field which may be affecting atomisation and that the air is supersonic locally around the valve constriction. The optical images confirm an incredibly complex regime under and between the valves. Capturing the fluid dynamics and atomisation processes with the introduction of a closed volume and injected fuel spray are the next steps to understanding the atomisation regimes and narrowing down the dominating phenomena and hypothesis.

Although the initial results from the optical work are still in preliminary stage and are rather inconclusive in addressing in detail the complex phenomena taking place, they still provide valuable insight to start unpicking the low emissions reported in Section 2.2. Demonstrating that the working fluid conditions upstream of the valve are creating flow structures and shockwaves which are not typically found in reciprocating ICEs. This could lead to the next step increase in atomisation through air dominant phenomena for the RSCE, future SCEs and other concepts where high-pressure air is readily available. Future work will introduce fuel injection and a closed volume to observe fuel atomisation and provide further insight into the hypotheses discussed in this initial piece of work.

\section{Conclusions}

The RSCE shows promise for achieving both a step improvement in efficiency and low emissions but understanding the combustion system is integral to the capitalisation and realisation of the concepts full potential. This paper presents initial test bed results of incylinder pressure trace and emissions in the SCCRE compared to conventional Diesel ICEs. 
It can be seen from these comparisons that there is a form of enhanced mixing but lower reactivity that is inducing a combustion PRR of $1.0 \mathrm{MPa} / \mathrm{CAD}$ and achieving a low FSN plateau at $0.8 \mathrm{MPa}$ lower than that of a conventional Diesel ICE. As conventional modern Diesel engines predominantly achieve high mixing and atomisation through increased fuel injector pressures, this would suggest that the unique inlet air conditions and dynamics in the SCCRE and RSCE are of more importance to achieve low emissions than rail pressure alone in these and other SCEs.

Three hypotheses are proposed that could be causing the increased rate of mixing and low emissions observed from the test bed data. Summarising, these hypotheses suggests that the enhanced mixing is driven by 1 . Increased velocity, swirl and microturbulences. 2 . Impinging Jet, Airblast \& Crossflow Atomisation. 3. Pressure \& Shock waves.

Lastly, images from recent Schlieren work characterising the cylinder flow field are reported and discussed to provide insight to the hypotheses. The imaging agrees with past CFD work that suggested the flow is supersonic and has gone further by demonstrating that bow shocks and Mach disks are created in the flow field, at least initially at IVO, and penetrate substantially into the combustion chamber. Supersonic flow, bow shocks and Mach disks are not found in conventional ICEs, making their presence in SCEs and the SCCRE and RSCE unique but not surprising, given the choked flow conditions. This is confirmed by calculation of velocity through the valve constriction. The original goal of starting to unpick the unique flow and atomisation processes has been achieved through hypothesis and initial experimentation. However, deducing the exact dominating hypothesis requires further experimental work.

Further investigation is needed to understand and improve the mixing and combustion in the RSCE and ascertain the fundamental processes affecting air injection, fuel mixing and combustion events. Literature is limited is this area to allow validation of models with representative conditions, i.e., supersonic expanding gas interfacing with liquid diesel in a closed volume at high pressure $(>1.0 \mathrm{MPa})$. The Schlieren work presented has confirmed supersonic conditions are present in the RSCE, but more work needs to be undertaken, including whole field of view, closed volume, and injection imaging, in the future. Other optical techniques, such as PIV, will be required to correlate and validate experimental velocities against past and future CFD studies. As the primary atomisation phenomenon is currently not fully understood, there is scope to improve and optimise the injection and combustion system. Though not fully utilised in the past, due to conventional ICE architectures, working fluid driven atomisation has the potential to improve mixing, combustion, emissions, and efficiency in future SCEs, RSCEs and other combustion systems. With the potential to produce low emissions (Euro VI onwards) in-cylinder.

Author Contributions: Conceptualisation, S.A.H., K.V. and R.E.M.; methodology, S.A.H., K.V. and R.E.M.; validation, S.A.H.; formal analysis, S.A.H.; investigation, S.A.H., G.d.S. and W.R.; resources, G.d.S. and W.R.; data curation, S.A.H., G.d.S. and W.R.; writing-original draft preparation, S.A.H.; writing-review and editing, S.A.H., K.V. and R.E.M.; visualisation, S.A.H.; supervision, K.V. and R.E.M.; project administration, S.A.H., K.V. and R.E.M.; funding acquisition, K.V. and R.E.M. All authors have read and agreed to the published version of the manuscript.

Funding: The authors acknowledge funding by the UK's Engineering and Physical Science Research Council support through the grant EP/P012744/1.

Acknowledgments: The authors would like to the Advanced Manufacturing and Research Centre at the University of Sheffield for their help and the use of their facilities.

Conflicts of Interest: The authors declare no conflict of interest. The funders had no role in the design of the study; in the collection, analyses, or interpretation of data; in the writing of the manuscript, or in the decision to publish the results. 


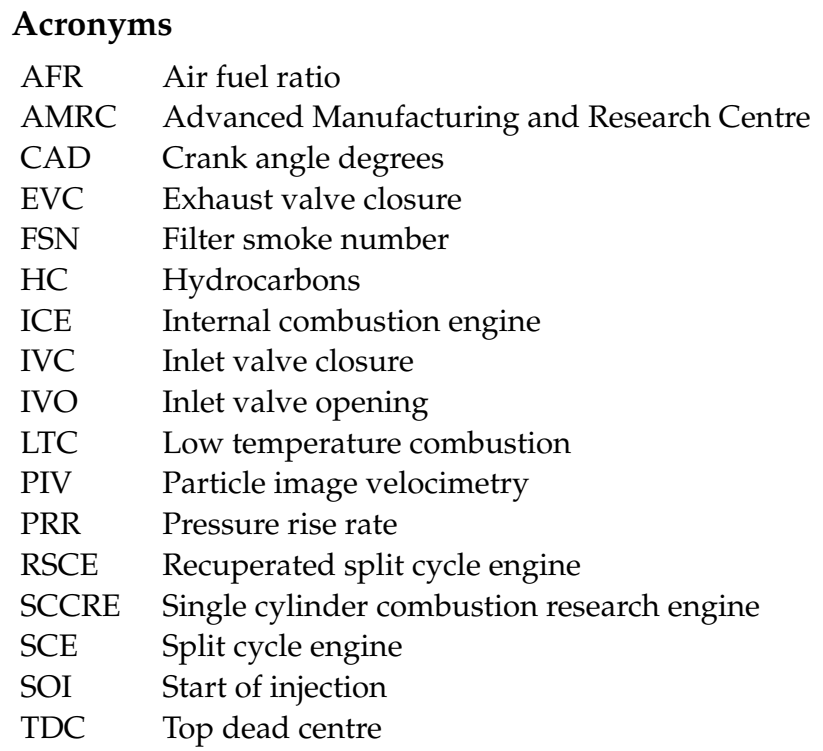

\section{References}

1. ERTRAC CO2-Evaluation Group. Report from ERTRAC $\mathrm{CO}_{2}$ Integrated Approach; ERTRAC CO2-Evaluation Group: Brussels, Belgium, 2017.

2. Siegemund, S.; Trommler, M.; Kolb, O.; Zinnecker, V.; Schmidt, P.; Weindorf, W.; Zittel, W.; Raksha, T.; Zerhusen, J. E-Fuels Study. The Potential of Electricity-Based Fuels for Low-Emission Transport in the EU; Deutsche. Energie-Agentur GmbH: Berlin, Germany, 2017.

3. Automotive Council UK. Thermal Propulsion Systems Roadmap 2020; Automotive Council UK: London, UK, 2021.

4. Delgado, O.; Lutsey, N. The U.S. SuperTruck Program: Expediting the Development of Advanced Heavy-Duty Vehicle Efficiency Technologies; The International Council on Clean Transportation: Washington, DC, USA, 2014.

5. Owen, N.; Treccarichi, F.; Atkins, A.; Selvaraj, A.; Barnes, D.; Besant, T.; Morgan, R. A Practical Recuperated Split Cycle Engine for Low Emissions and High Efficiency; SAE Technical Paper 2019-24-0190; SAE International: Warrendale, PA, USA, 2019. [CrossRef]

6. Morgan, R.E.; Jackson, N.; Atkins, A.; Dong, G.; Heikal, M.; Lenartowicz, C. The Recuperated Split Cycle-Experimental Combustion Data from a Single Cylinder Test Rig. SAE Int. J. Engines 2017, 10, 2596-2605. [CrossRef]

7. Morgan, R.; Khalid, F.; Atkins, A.; Harvey, S.; Firmansyah, F.; Mason, D.; Vogiatzaki, K.; Heikal, M. Towards zero emission engines through the adoption of combustion-lead engine design realised using a split cycle topology. In Proceedings of the THIESEL 2018 Conference on Thermo- and Fluid Dynamic Processes in Direct Injection Engines, Valencia, Spain, 11-14 September 2018.

8. Morgan, R.; Lenartowicz, C.; Vogiatzaki, K.; Harvey, S.; Kennaird, D.; Owens, N.; Pickett, R.; Atkins, A. The Ultra Low Emissions Potential of the Recuperated Split Cycle Combustion System; SAE Technical Paper 2019-24-0189; SAE International: Warrendale, PA, USA, 2019. [CrossRef]

9. Musu, E.; Gentili, R.; Reitz, R.D. Homogeneous Charge Progressive Combustion (HCPC): CFD Study of an Innovative Diesel HCCI Concept; SAE Technical Paper 2009-01-1344; SAE International: Warrendale, PA, USA, 2009. [CrossRef]

10. Musu, E.; Rossi, R.; Gentili, R.; Reitz, R.D. Clean Diesel Combustion by Means of the HCPC Concept. SAE Int. J. Engines 2010, 3 , 964-981. [CrossRef]

11. Rossi, R.; Musu, E.; Frigo, S.; Gentili, R.; Reitz, R.D. Simultaneous Reduction of Soot and NO X Emissions by Means of the HCPC Concept: Complying with the Heavy Duty EURO 6 Limits without Aftertreatment System; SAE Technical Paper 2013-24-0093; SAE International: Warrendale, PA, USA, 2013. [CrossRef]

12. Lam, N.; Tuner, M.; Tunestal, P.; Andersson, A.; Lundgren, S.; Johansson, B. Double Compression Expansion Engine Concepts: A Path to High Efficiency. SAE Int. J. Engines 2015, 8, 1562-1578. [CrossRef]

13. Lam, N.; Andersson, A.; Tunestal, P. Double Compression Expansion Engine Concepts: Efficiency Analysis over a Load Range; SAE Technical Paper 2018-01-0886; SAE International: Warrendale, PA, USA, 2018. [CrossRef]

14. Babayev, R.; Ben Houidi, M.; Andersson, A.; Johansson, B. Isobaric Combustion: A Potential Path to High Efficiency, in Combination with the Double Compression Expansion Engine (DCEE) Concept; SAE Technical Paper 2019-01-0085; SAE International: Warrendale, PA, USA, 2019. [CrossRef]

15. Coney, M. A thermodynamic analysis of a novel high efficiency reciprocating internal combustion engine-the isoengine. Energy 2004, 29, 2585-2600. [CrossRef]

16. Coney, M.W.; Linnemann, C.; Sugiura, K.; Goto, T. First prototype of the high-efficiency isoengine. Power Eng. 2004, 5-19.

17. Dong, G.; Morgan, R.; Heikal, M. A novel split cycle internal combustion engine with integral waste heat recovery. Appl. Energy 2015, 157, 744-753. [CrossRef] 
18. Dong, G.; Morgan, R.E.; Heikal, M.R. Thermodynamic analysis and system design of a novel split cycle engine concept. Energy 2016, 102, 576-585. [CrossRef]

19. Phillips, F.; Gilbert, I.; Pirault, J.-P.P.; Megel, M. Scuderi Split Cycle Research Engine: Overview, Architecture and Operation. SAE Int. J. Engines 2011, 4, 450-466. [CrossRef]

20. Meldolesi, R.; Bailey, G.; Lacy, C.; Gilbert, I.; Pirault, J.-P.; Perkins, A. Scuderi Split Cycle Fast Acting Valvetrain: Architecture and Development. SAE Int. J. Engines 2011, 4, 467-481. [CrossRef]

21. Gilles, F.W. Improvement in Gas Engines. Sci. Am. 1876, 2, 691. [CrossRef]

22. Morgan, R.; Dong, G.; Panesar, A.; Heikal, M. A comparative study between a Rankine cycle and a novel intra-cycle based waste heat recovery concepts applied to an internal combustion engine. Appl. Energy 2016, 174, 108-117. [CrossRef]

23. Coney, M.W.; Stephenson, P.; Malmgren, A.; Linnemann, C.; Morgan, R.E. Development of a Reciprocating Compressor Using Water Injection to Achieve Quasi- Isothermal Compression. In Proceedings of the International Compressor Engineering Conference, Purdue University, West Lafayette, IN, USA, 16-19 July 2002; p. 10.

24. Stephenson, P.L.; Coney, M.; Hill, W.; Park, B.; Sn, W. Computer modelling of isothermal compression in the reciprocating compressor of a complete isoengine. In Proceedings of the 16th Annual Conference on Liquid Atomization and Spray Systems, ILASS EUROPE, Darmstadt, Germany, 11-13 September 2000.

25. Gopal, J.M.; Tretola, G.; Morgan, R.; de Sercey, G.; Atkins, A.; Vogiatzaki, K. Understanding sub and supercritical cryogenic fluid dynamics in conditions relevant to novel ultra low emission engines. Energies 2020, 13, 3038. [CrossRef]

26. Jaya Vignesh, M.; Harvey, S.; Atkins, A.; Atkins, P.; De Sercey, G.; Heikal, M.; Morgan, R.; Vogiatzaki, K. Use of cryogenic fluids for zero toxic emission hybrid engines. In Internal Combustion Engines and Powertrain Systems for Future Transport 2019: Proceedings of the International Conference on Internal Combustion Engines and Powertrain, Birmingham, UK, 11-12 December 2019; IMECHE, Ed.; CRC Press: Boca Raton, FL, USA, 2019; ISBN 978-0-367-90356-5.

27. Olofsson, E.; Alvestig, P.; Bergsten, L.; Ekenberg, M.; Gawell, A.; Larsén, A.; Reinmann, R. A High Dilution Stoichiometric Combustion Concept Using a Wide Variable Spark Gap and In-Cylinder Air Injection in Order to Meet Future $\mathrm{CO}_{2}$ Requirements and World Wide Emission Regulations; SAE Technical Paper 2001-01-0246; SAE International: Warrendale, PA, USA, 2001. [CrossRef]

28. Seo, Y.-H.H. Development of Air-Assisted Injection System for MPI Gasoline Engine; SAE Technical Paper 981056; SAE International: Warrendale, PA, USA, 1998. [CrossRef]

29. Sureshkumar, J.; Elayaraja, R.; Mallikarjuna, J.M.; Venkitachalam, G. Transient Spray Characteristics of Air Assisted Fuel Injection; SAE Technical Paper 2015-01-0920; SAE International: Warrendale, PA, USA, 2015. [CrossRef]

30. Cathcart, G.; Zavier, C. Fundamental Characteristics of an Air-Assisted Direct Injection Combustion System as Applied to 4-Stroke Automotive Gasoline Engines; SAE Technical Paper 2000-01-0256; SAE International: Warrendale, PA, USA, 2000. [CrossRef]

31. Brogan, M.S.; Swallow, D.; Brisley, R.J.; Worth, D.; Yang, K. A New Approach to Meeting Future European Emissions Standards with the Orbital Direct Injection Gasoline Engine; SAE Technical Paper 2000-01-2913; SAE International: Warrendale, PA, USA, 2000. [CrossRef]

32. Koci, C.; Florea, R.; Das, S.; Walls, M.; Simescu, S.; Roberts, C. Air-Assisted Direct Injection Diesel Investigations; SAE Technical Paper 2013-01-0907; SAE International: Warrendale, PA, USA, 2013. [CrossRef]

33. Cathcart, G.; Tubb, J. Application of Air Assisted Direct Fuel Injection to Pressure Charged Gasoline Engines; SAE Technical Paper 2002-01-0705; SAE International: Warrendale, PA, USA, 2002. [CrossRef]

34. Boretti, A.A.; Jin, S.H.; Zakis, G.; Brear, M.J.; Attard, W.; Watson, H.; Carlisle, H.; Bryce, W. Experimental and Numerical Study of an Air Assisted Fuel Injector for a D.I.S.I. Engine; SAE Technical Paper 2007-01-1415; SAE International: Warrendale, PA, USA, 2007. [CrossRef]

35. Firmansyah; Morgan, R.; Heikal, M.R.; Aziz, A.R.A. Effect of Pressure in Crossover Port to the In-Cylinder Flow of Split-Cycle Engine; AIP Publishing LLC: Melville, NY, USA, 2018; p. 080003. [CrossRef]

36. Gerbino, F.; Morgan, R.; Atkins, P.; Vogiatzaki, K. Assessment of modelling capability for numerical simulations for designing higher efficiency and lower emission systems. In Proceedings of the International Conference on Energy and Sustainable Futures, Nottingham, UK, 9-11 September 2019.

37. Jia, T.-M.; Li, G.-X.; Yu, Y.-S.; Xu, Y.-J. Effects of ultra-high injection pressure on penetration characteristics of diesel spray and a two-mode leading edge shock wave. Exp. Therm. Fluid Sci. 2016, 79, 126-133. [CrossRef]

38. Kocsis, M.C.; Joo, S.; Briggs, T.; Alger, T. Impact of Swirl Ratio on Combustion Performance of a Non-Pent Roof Combustion Chamber Engine; SAE Technical Paper 2015-01-0743; SAE International: Warrendale, PA, USA, 2015. [CrossRef]

39. Janhunen, T. HCCI-Combustion in the Z Engine; SAE Technical Paper 2012-01-1132; SAE International: Warrendale, PA, USA, 2012. [CrossRef]

40. Janhunen, T. HCCI-Combustion in the Z Engine-Part II; SAE Technical Paper 2012-01-1573; SAE International: Warrendale, PA, USA, 2012. [CrossRef]

41. Day, M.; Tachibana, S.; Bell, J.; Lijewski, M.; Beckner, V.; Cheng, R.K. A combined computational and experimental characterization of lean premixed turbulent low swirl laboratory flames: I. Methane flames. Combust. Flame 2012, 159, 275-290. [CrossRef]

42. Day, M.; Tachibana, S.; Bell, J.; Lijewski, M.; Beckner, V.; Cheng, R.K. A combined computational and experimental characterization of lean premixed turbulent low swirl laboratory flames II. Hydrogen flames. Combust. Flame 2015, 162, 2148-2165. [CrossRef]

43. Chehroudi, B. Recent experimental efforts on high-pressure supercritical injection for liquid rockets and their implications. Int. J. Aerosp. Eng. 2012, 2012, 121802. [CrossRef] 
44. Leong, M.Y.; McDonell, V.G.; Samuelsen, G.S. Mixing of an Airblast-Atomized Fuel Spray Injected into a Crossflow of Air; Nasa/Cr2000-210467; University of California: Irvine, CA, USA, 2000.

45. Ragucci, R.; Bellofiore, A.; Cavaliere, A. Breakup and breakdown of bent kerosene jets in gas turbine conditions. Proc. Combust. Inst. 2007, 31, 2231-2238. [CrossRef]

46. Surya Prakash, R.; Gadgil, H.; Raghunandan, B.N. Breakup processes of pressure swirl spray in gaseous cross-flow. Int. J. Multiph. Flow 2014, 66, 79-91. [CrossRef]

47. Karagozian, A.R. Transverse jets and their control. Prog. Energy Combust. Sci. 2010, 36, 531-553. [CrossRef]

48. Seay, J.E.; Samuelsen, G.S. Atomization and Dispersion of a Liquid Jet Injected into a Crossflow of Air; Nasa/Cr-1997-0010250; University of California: Irvine, CA, USA, 1997.

49. Surya Prakash, R.; Sinha, A.; Tomar, G.; Ravikrishna, R.V. Liquid jet in crossflow-Effect of liquid entry conditions. Exp. Therm. Fluid Sci. 2018, 93, 45-56. [CrossRef]

50. Ren, Z.; Wang, B.; Xiang, G.; Zhao, D.; Zheng, L. Supersonic spray combustion subject to scramjets: Progress and challenges. Prog. Aerosp. Sci. 2019, 105, 40-59. [CrossRef]

51. Chehroudi, B.; Talley, D. Interaction of acoustic waves with a cryogenic nitrogen jet at sub- and supercritical pressures. In Proceedings of the 40th AIAA Aerospace Sciences Meeting \& Exhibit; American Institute of Aeronautics and Astronautics, Reston, Virigina, 14-17 January 2002. [CrossRef]

52. Kook, S.; Pickett, L. Effect of Ambient Temperature and Density on Diesel-Spray-Generated Shock Waves. In Proceedings of the ILASS Americas 2008: 21st Annual Conference on Liquid Atomization and Spray Systems, Orlando, FL, USA, 18-21 May 2008. [CrossRef]

53. Salvador, F.J.; De la Morena, J.; Taghavifar, H.; Nemati, A. Scaling spray penetration at supersonic conditions through shockwave analysis. Fuel 2020, 260, 116308. [CrossRef]

54. Oschwald, M.; Smith, J.J.; Branam, R.; Hussong, J.; Schik, A.; Chehroudi, B.; Talley, D. Injection of fluids into supercritical environments. Combust. Sci. Technol. 2006, 178, 49-100. [CrossRef]

55. Chehroudi, B. Physical hypothesis for the combustion instability in cryogenic liquid rocket engines. J. Propuls. Power 2010, 26, 1153-1160. [CrossRef]

56. Manin, J.; Crua, C.; Pickett, L.M. Transcritical mixing of sprays for multi-component fuel mixtures. In Proceedings of the ILASS-Europe 2017: 28th Conference on Liquid Atomization and Spray Systems, Valencia, Spain, 6-8 September 2017. [CrossRef]

57. Lazzaro, M.; Catapano, F.; Sementa, P. Experimental Characterization of Methane Direct Injection from an Outward-Opening Poppet-Valve Injector; SAE Technical Paper 2019-24-0135; SAE International: Warrendale, PA, USA, 2019. [CrossRef] 